that his aspirations are incommensurate with his abilities. Now for the first time the view is tenable that society will not tolerate the waste involved in maintaining this conception, already largely illusory, of the individual's right to freedom of choice of occupation. A guidance far more positive and compelling than hitherto will obviously enhance the importance of the agencies responsible for it and, moreover, all teachers, supervisors and curriculum. makers will be increasingly preoccupied with their function of exploring and testing their pupils' capabilities.

\section{Burden Mental Research Trust}

Aт a meeting held recently in London, the committee of administration had before it reports of the first year's working of the Burden Mental Research Trust, which Mrs. R. G. Burden endowed a short time ago with $£ 10,000$. The investigations contemplated by the Committee are being carried out by Dr. J. A. Fraser Roberts, assisted by Dr. R. M. Norman and Dr. Ruth Griffiths. An extensive survey of the mentally normal as well as the mentally abnormal has been initiated, and when the Trust eventually publishes its final report, it is hoped and expected that much valuable information will be fortheoming as to the nature of the transmission of mental abilities and disabilities. The Trust has also arranged for the co-operation of other distinguished investigators from different parts of Great Britain, one of whom-Dr. Shepherd Dawson of Glasgowhas already complied with the request of the Com. mittee.

\section{Vital Statistics for 1934}

The provisional figures of the vital statistics for the year 1934 have been issued by the General Register Office, Somerset House. They are as follows : for England and Wales : live births, 14.8, and deaths (crude rate), $11 \cdot 8$ per 1,000 resident population, and infant mortality rate (deaths under 1 year per 1,000 registered live births), 59. The birth rate shows an increase of 0.4 per 1,000 above the low record of 1933, and is noteworthy as being the only increase recorded since 1920 , except in 1928 , when there was a slight improvement of 0.1 following an exceptional fall in the previous year. The crude death rate is 0.5 below that for 1933, and only 0.4 above the lowest recorded in 1930 . The infant mortality rate is 5 per 1,000 below that for 1933, and is the lowest recorded, the previous lowest being 60 for 1930 .

\section{Scientific Exhibition at Bombay}

THe staff and students of the Royal Institute of Science, Bombay, held a most successful Scientific Exhibition on December 13-18, 1934, in aid of the Bombay hospitals. In a country like India which possesses few scientific museums, such exhibitions have great educational value, and the example of the Bombay Science Institute might well be followed elsewhere. About a thousand pounds were realised for the hospital fund. It may be remembered that similar exhibitions were organised in London several years ago in connexion with the King Edward's Hospital Fund and were very successful.

\section{Solid and Liquid Gases in Science and Industry}

THE low temperature exhibition, which is being arranged by the Science Museum, has already been mentioned in these columns; we now learn from the director of the Museum, Col. E. E. B. Mackintosh, that the opening date has been postponed until March 1936 in order to give a longer time for the preparation of the exhibits. The exhibition will remain open until the end of May and will therefore immediately precede the Seventh International Congress of Refrigeration to be held in Holland in May 1936. Promises of several interesting exhibits have already been received and the committee, under the chairmanship of Mr. H. T. Tizard, has made considerable progress with the arrangements. The other members of the committee are Dr. Ezer Griffiths, Prof. P. Kapitza, Prof. F. A. Lindemann, Prof. J. C. MeLennan, Lord Melchett, Mr. C. C. Paterson, Dr. J. D. Pollock, Prof. F. Simon, Prof. M. W. Travers and Mr. R. S. Whipple, while the Museum officer responsible for carrying out the arrangements is Mr. T. C. Crawhall, who was also responsible for the Refrigeration Exhibition recently held in the Science Museum.

\section{Standardisation of Hospital Equipment}

A Copy of a report made by a Committee set up in 1931 by the Public Health Congress Council, 13 Victoria Street, London, S.W.1, to explore possibilities of standardisation of hospital equipment in Great Britain has been forwarded to county and county borough councils by the Ministry of Health (Circular 1410). It is concluded that some 30 per cent of the total maintenance costs of hospitals is incurred in respect of goods that can be readily standardised, without affecting the efficient working of institutions or interfering with the requirements of their professional staffs. It is shown that by standardisation and bulk purchasing, economies of $10-30$ per cent may be effected. Standardisation is applicable to hospital furniture and textiles, crockery, cutlery, surg. ical materials and rubber goods, office requisites and many other articles ; examples are given of economies that can be effected in this way, and reports of com. mittees that have considered the subject in Germany and in New York are given in appendixes.

\section{New Map of Hispanic America}

Is 1920 the American Geographical Society began the compilation of a map of South America from existing sources. The available material is considerable, but so far no general map had been produced in any sense representative of the existing informa. tion. The Society now announces the publication of fifty of the hundred and two sheets which together will cover America from Mexico to Tierra del Fuego. Already large blocks including most of Chile and much of Brazil are ready. The scale is $1: 1,000,000$ and the style is in conformity with the International Map of the World on that scale. The Society also announces 